before the IPCC report's release, Rahmstorf and his colleagues argue that sea-level rises will be close to the worst-case predictions of climate models (S. Rahmstorf et al. Science doi:10.1126/science.1136843; 2007). "If anything, the IPCC has been conservative," he says.

Key sticking points include the inability of global climate models to produce the amount of sea-level rise observed over the past couple of decades and whether ice flow at the bases of glaciers is accelerating or not. How volatile Antarctic and Greenland glaciers might become in a warmer world is therefore pretty much guesswork.

For the first time, the IPCC report predicts how changing dimate might affect particular regions of the world. But these forecasts are only in their infancy, modellers warn. For some areas, models predict specific and well understood effects, such as hotter summers in Spain and smaller snowpacks (the accumulation of snow each season) in the Rocky Mountains in the United States. But improved analyses that incorporate clouds, snow and ice into the models must be developed if regional predictions are to become more accurate, says Rasmus Benestad, a climate modeller at the Norwegian Meteorological Institute in Oslo.

Extreme weather is another example of the remaining uncertainties. Climate researchers believe that storms and heavy rainfall will become more frequent as the planet warms. But pinning down where and when that might happen is not so simple.

In the tropics, rising sea-surface temperatures can be linked in a relatively straightforward manner to storm formation, and the case for more intense storms seems more or less settled. But in the mid-latitudes, where atmospheric processes are more complex, some climate models predict more storms whereas others do not.

Improving the models, experts say, requires better data. Gaps and errors in observations are attributable to many causes: snowfall gauges that ice up, oceanographic floats that get lost, and changeovers in satellites that throw off carefully calibrated trends, to name but a few. Cloud and storm records urgently need to be reprocessed using uniform techniques, says Kevin Trenberth, a senior scientist at the National Center for Atmospheric Research in Boulder, Colorado, and coordinating lead author of the report's chapter on surface and atmospheric change.

${ }^{\alpha}$ The IPCC report is a consensus report, and one that develops over nearly three years," he says. "This means that it is not the leading - or bleeding - edge of the science."

Quirin Schiermeier

\section{Data keep flooding in}

The 2007 report of the Intergovernmental Panel on Climate Change (IPCC) represents the work of thousands of researchers, compiled and summarized by hundreds of climatologists. Nominally, the cut-off for inclusion in the assessment was the end of 2005 , allowing a year for the panel to make sense of the vast tracts of data. But notable research arising after that date will not have escaped attention. Here is a round-up of some of the most prominent studies.

\section{Greenland ice}

Greenland is losing ice at

an ever-increasing rate, according to data from the GRACE gravity-measuring satellite (J.L.Chen, C.R. Wilson \& B.D. Tapley Science 313,1958-1960; 2006).

\section{Antarctic air}

Weather balloons reveal that the troposphere above Antarctica has warmed by $0.5-0.7^{\circ} \mathrm{C}$ perdecade over the past 30 years, although it is not clear why (J. Turner,

T.A. Lachlan-Cope,

S. Colwell, G. J. Marshall \&

W. M. Connolley Science 311, 1914-1917; 2006).

\section{Established forests}

Old forests keep soakingup atmospheric carbon long after they reach maturity, according to measurements from China. Soil carbon in a forestreserve in Guangdong increased by $68 \%$ in 25 years (G. Zhou et al. Soience 314, 1417; 2006).

\section{Atlantic currents}

The Gulf Stream, which brings heat from the tropics to the North Atlantic, weakened by $10 \%$ between 1200 and 1850 , during the cold spell known as the Little lce Age. The authors suggest that this demonstrates the link between this ocean current and temperatures in northern Europe (D. C. Lund, J, LynchStieglitz \& W. B. Curry Nature 444, 601-604; 2006).

\section{Atlantic hurricanes}

Risingsea-surface

temperatures correlate

strongly with the observed

increase in the number of

category 4 and 5 Atlantic hurric anes between 1970 and 2004. Other factors that affect hurricane formation, such as wind shear, do not seem to have increased in line with the upward trend (C. D. Hoyos, P. A. Agudelo, P. J. Webster \& J. A. Curry Science 312, 94-97; 2006).

\section{River runoff}

More carbon dioxide in the atmosphere leads to plants losing less water by transpiration, a model suggests. This could affect the amount of fresh water available for human use.
(N. Gedney et al Nature 439, 835-838;2006).

\section{Polar temperatures} years in an Antarctic ice core show that warming events have tended to seesaw back and forth between the poles (EPICA Community Members Nature 444, 195-198; 2006).

\section{Ocean temperatures}

The up per layers of the oceans cooled, on average, between 2003 and 2005. Factoring in this downturn, the rate of warming in these layers between 1993 and 2005 was equivalent to 0.33 watts per squaremetre over the whole of the planet's surface (J.M. Lyman, J. K. Willis \& G. C. Johnson Geophys Res Lett. 33, L18604; 2006).

\section{Sea levels}

If the rate of sea-level rise is proportional to the global rise in temperature since preindustrial times, sealevels could rise by up to 1.4 metres by 2100 ( $S$. Rahmstorf Science 315, 368-370; 2007).

Michael Hopkin
Bubbles dating back 150,000

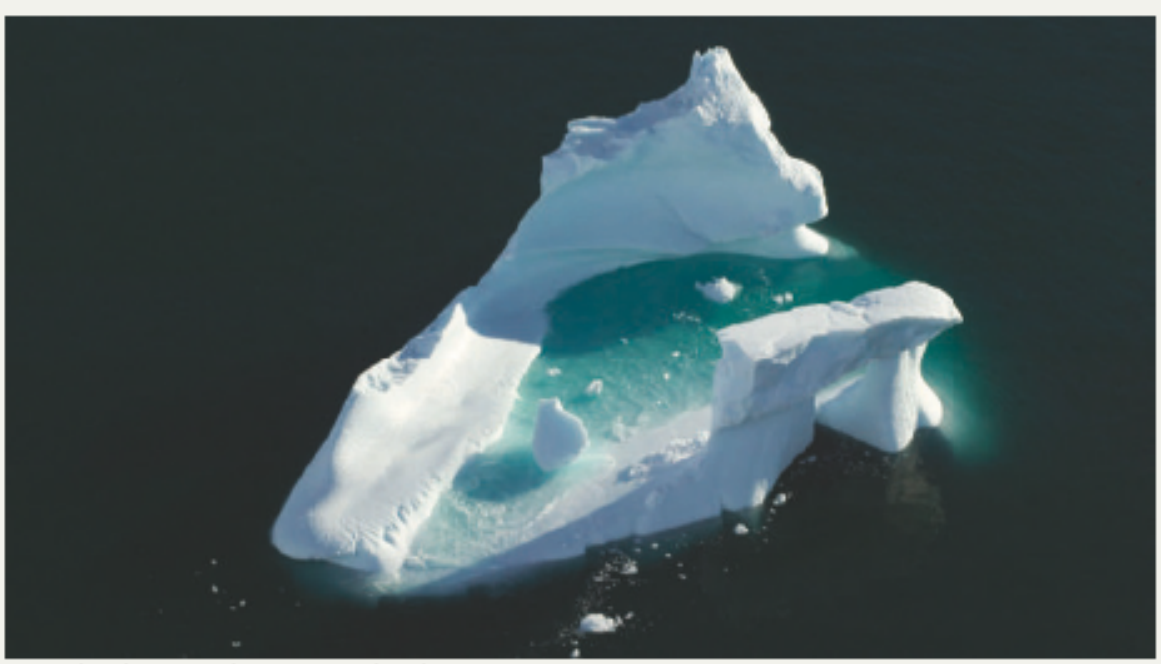

Greenland ice is melting faster than before. 